\title{
Okan Ozseker, Forging the Border : Donegal and Derry in Times of Revolution, 1911-1925
}

\section{Christophe Gillissen}

\section{(2) OpenEdition}

\section{Journals}

Édition électronique

URL : https://journals.openedition.org/etudesirlandaises/8971

DOI : 10.4000/etudesirlandaises.8971

ISSN : 2259-8863

\section{Éditeur}

Presses universitaires de Caen

\section{Édition imprimée}

Date de publication : 24 septembre 2020

Pagination : 122-123

ISSN : 0183-973X

\section{Référence électronique}

Christophe Gillissen, « Okan Ozseker, Forging the Border : Donegal and Derry in Times of Revolution, 1917-1925 », Études irlandaises [En ligne], 45-1 | 2020, mis en ligne le 24 septembre 2020, consulté le 15 novembre 2022. URL : http://journals.openedition.org/etudesirlandaises/8971 ; DOI : https:// doi.org/10.4000/etudesirlandaises.8971

\section{(c) (i) (2)(2)}

Creative Commons - Attribution - Pas d'Utilisation Commerciale - Partage dans les Mêmes Conditions 4.0 International - CC BY-NC-SA 4.0

https://creativecommons.org/licenses/by-nc-sa/4.0/ 
As for Marina Carr (p. 185-220), focusing on Portia Coughlan, By the Bog of Cats, and Woman and Scarecrow, Price's analysis is stimulating. He links Carr's plays with Wilde's Salomé, through the status of her tragic heroines, whom he views as Dionysian women due to their rejection of distinctions between nature and humanity, as well as an opposition between masculine and feminine usage of language. Concluding with more recent plays, Price shows how Carr has refashioned Wildean aesthetics to define her own.

Oscar Wilde and Contemporary Irish Drama: Learning to Be Oscar's Contemporary has a clear, balanced structure, which paradoxically might be its weak point. Indeed, although it is well documented, one could argue that it devotes too much space to Friel and Murphy, without putting forth very convincing points. On the other hand, in view of what Price has to say about Kilroy, McGuinness or Carr, one feels that longer chapters on them would have given a greater impact to the book.

Thierry Dubost

\section{Okan Ozseker, Forging the Border: Donegal and Derry in Times of Revo- lution, 1911-1925, Newbridge, Irish Academic Press, 2019, 302 p.}

Alors que les négociations sur le Brexit n'en finissent pas de buter sur la question de la frontière irlandaise et que la perspective d'une seconde partition de l'Irlande ne peut être écartée, cet ouvrage sur la période révolutionnaire dans les comtés de Donegal et de Derry permet de mieux cerner les enjeux de la division territoriale dans cette partie de l'île, ainsi que les événements qui y conduisirent et la manière dont la population y réagit il y a un siècle.

Si la décennie des commémorations a donné lieu à de nombreuses publications sur la période 1911-1925, il s'agit ici d'une approche relevant de l'histoire régionale dans un territoire qui peut être considéré comme un "microcosme» de la question d'Irlande à l'époque (p. 202). Il présente par ailleurs des spécificités intéressantes, telles que la présence d'une forte communauté unioniste radicale dans le comté de Londonderry, un Donegal qui était un bastion du nationalisme conservateur, le statut hautement symbolique de la ville de Derry/Londonderry revendiquée par les deux camps, et un impact particulièrement important de la partition pour d'évidentes raisons géographiques. De manière inattendue cependant, le Donegal se caractérisa par un niveau de violence plus faible qu'ailleurs en Irlande, même si le comté de Derry connut bien des émeutes, affrontements et exactions, mais à une échelle moindre qu'à Belfast.

Lors de la crise du Home Rule, en janvier 1913, l'élection partielle de Derry fut perçue par tous comme un test décisif, tant en Irlande qu'en Grande-Bretagne (p. 37-38). Même si elle se trouvait dans le comté de Londonderry, elle était 
considérée comme la «vraie capitale» du Donegal (p. 7) par les catholiques. Au terme d'une campagne particulièrement disputée, le candidat présenté par les nationalistes, David Hogg, libéral d'origine écossaise, remporta le siège avec seulement cinquante-sept suffrages d'avance sur le candidat unioniste, le colonel Pakenham, avec un taux de participation de $95 \%$ ! Pour les unionistes, la perte d'une ville défendue par leurs ancêtres lors du siège de 1688-1689 fut un revers cuisant.

Pourtant, jusqu'à l'été 1913 et les émeutes qui suivirent une manifestation loyaliste à Londonderry, les nationalistes ne prêtèrent guère d'importance à la mobilisation unioniste contre le Home Rule alors qu'elle s'intensifiait. À leur décharge, la police aussi sous-estima longtemps le phénomène, du moins jusqu'aux émeutes du mois d'août 1913. Quant à la mobilisation nationaliste, elle se fit sous l'égide de l'Ancient Order of Hibernians, contrairement au reste de l'île où le Sinn Féin était le principal acteur du nationalisme radical. Après le soulèvement de 1916, le Sinn Féin tenta de s'implanter dans la région, non sans succès, mais par la suite le Nord-Ouest se prononça très majoritairement en faveur du Traité anglo-irlandais, en partie parce qu'il prévoyait qu'une Commission de démarcation (Boundary Commission) réviserait le tracé de la frontière. Les nationalistes espéraient qu'une grande partie du comté de Londonderry serait alors attribuée à l'État libre d'Irlande, pour le plus grand bénéfice du Donegal. La déception fut d'autant plus grande en 1925, lorsque les travaux de la Commission aboutirent à entériner la frontière de 1920.

L'ouvrage est fort bien documenté : l'auteur s'appuie notamment sur la presse locale et nationale, sur les rapports de police et sur de nombreux témoignages de l'époque, pour livrer un compte rendu exhaustif de la situation dans le NordOuest de l'île à une époque décisive de l'histoire irlandaise. Par moments cette surabondance d'informations gêne la lecture, la fluidité du texte étant entravée par des faits trop nombreux, et on regrettera quelques choix contestables dans la présentation, comme une carte du Donegal au titre elliptique ou une carte de Londonderry datant de 1837. Ces quelques imperfections peuvent s'expliquer par le fait qu'il s'agit d'une version remaniée de la thèse de l'auteur, soutenue à Coleraine en 2017, mais quoi qu'il en soit le livre devrait s'imposer comme une lecture indispensable pour quiconque s'intéresse au sujet.

Christophe GiLlissen

\section{Henry Piers's Continental Travels, 1595-1598, Brian Mac Cuarta (ed.), Cam- bridge, Cambridge University Press (Camden Fifth Series; 54), 2018, 238 p.}

The 1607 Turas na dTaoiseach (most recently edited by Nollaig Ó Muraíle) is perhaps the best-known, early modern Irish travel memoir. In it, Tadhg Ó Cianáin, 